\title{
Application of Sinboron Fibrous Monoliths for Air Breathing Engine Applications
}

\author{
M.C.L.Patterson*, \\ Advanced Ceramics Research, 3292 East Hemisphere Loop, Tucson AZ, 85706 \\ M.Fulcher ${ }^{\dagger}$ \\ MarathonNorco Aerospace, 8310 Imperial Drive, Waco, TX 76712
}

J. Halloran ${ }^{\ddagger}$

Department of Materials Science and Engineering, University of Michigan, Ann Arbor, MI 48109-2136

and

R. $\operatorname{Signh}^{\S}$

University of Cincinatti, Dept of Chem. \& Mat'ls. Eng'rg, Cincinatti, OH 45221-0012

\begin{abstract}
Poor thermal shock and resistance to crack propagation have had a negative influence on the acceptance of ceramics for components in air breathing engine applications. In comparison with their metallic counterparts, they are less predictable and there is limited historical in-use data available. They have therefore been considered primarily for non-load bearing applications such as flaps and seals, flame holders and covers.

A fibrous monolith, ceramic hybrid between a $\mathrm{Si}_{3} \mathrm{~N}_{4}$ core with a weak $\mathrm{BN}$ interface has been evaluated for non-load bearing applications in air breathing engines where a high degree of thermal shock resistance is required. The fibrous monolith architecture confines damage to local regions and although the overall strength is typically reduced, the macroscopic damage tolerance and thermal shock resistance is improved over monolithic $S_{3} N_{4}$ of similar compositions. Two different architectural scales with a cell size of $150 \mu \mathrm{m}$ and $30 \mu \mathrm{m}$ were investigated. Both architectures showed a similar response with no loss in strength when quenched from below $800^{\circ} \mathrm{C}$ and no loss in modulus when quenched from $1000^{\circ} \mathrm{C}$ into water. Cyclic thermal shock from $600^{\circ} \mathrm{C}$ showed no change in modulus but at $1000^{\circ} \mathrm{C}$ a gradual drop in the modulus was observed. Microstructural assessment of the $\mathrm{Si}_{3} \mathrm{~N}_{4}$ core and $\mathrm{BN}$ phases showed microcracking of the $\mathrm{BN}$ phase following thermal shock but no discernable changes in the $\mathrm{Si}_{3} \mathrm{~N}_{4}$ phase. The thermal shock resistance of the $\mathrm{FM} \mathrm{Si}_{3} \mathrm{~N}_{4}$ / BN structure is improved over monolithic $\mathrm{Si}_{3} \mathrm{~N}_{4}$ due to the ability of the weak $\mathrm{BN}$ interface to preferentially microcrack and accommodate strain. Improved thermal shock resistance has been demonstrated in water quench tests as well as in a gas burner rig test where heating rates and temperatures more representative of those observed in engine applications have been investigated.
\end{abstract}

\section{Introduction}

Ceramics can offer improved thermal capability, oxidation resistance and weight advantages over their metallic counterparts and have for several years been considered for use in airbreathing engines. The adoption of ceramics into this area traditionally supplied by metals has been slower than predicted, in part due to perceived risks associated with limited data in the areas of manufacturing, performance, durability, maintenance and repair. Under the DARPA Ceramic Insertion program continuous fiber reinforced ceramic composites (CMCs) were developed

\footnotetext{
Director of Research and Technology, Suite 226, 4001, North $9^{\text {th }}$ Street, Arlington VA. Non-member Lead Engineer, MarathonNorco Aerospace, 8310 Imperial Drive, Waco, TX. Non-member

* Professor, Mater.Sci \& Engng. University of Michigan Ann Arbour. MI. Non-member

$\S$ Professor, University of Cincinatti, Dept of Chem. \& Mat'ls. Eng'rg, Cincinatti, OH Non-member
} 
and evaluated for use as flaps and seals on the F-110 and F-414 engine. These metal component were targeted for substitution by ceramics due to high maintenance costs which resulted from overheating during afterburner use and excessive wear on the metallic parts. CMCs were selected since they offer a higher toughness than monolithic ceramics and were capable of accumulating damage without catastrophic failure. Although now a production part, these CMC components are expensive to produce and alternative, lower cost materials have been considered for these and other hot section engine components such as combustors, fuel shields, flame holders vanes and blades. In the present study a silicon nitride $\left(\mathrm{Si}_{3} \mathrm{~N}_{4}\right)$ - boron nitride $(\mathrm{BN})$ composite material system (sinboron) is being evaluated for insertion as a fuel shield component in the GE 404 engine. The fuel shield is designed to prevent premature afterburner partition failure, which has recently been identified as the leading cause of unscheduled maintenance for this engine in the field.

The "Sinboron" fibrous monolith ceramic ${ }^{1}{ }^{2}$ consist of a fully dense network of polycrystalline $\mathrm{Si}_{3} \mathrm{~N}_{4}$ fibers each of which is surrounded by a sheath of weaker BN. Unlike CMCs where the weak fiber coating is very thin $(\sim 0.2 \mu \mathrm{m})$ and the fiber surface is smooth resulting in toughening by the sliding of the fiber within a matrix material, in fibrous monoliths the fiber coating is thick and there is no matrix phase in the conventional sense. Research has shown that the low shear strength cell boundaries such as BN accommodate the expansions and contractions during thermal cycling of the FM composite components, resulting in improved thermal shock resistance ${ }^{34}$, The weak interfaces deflect cracks and delaminate and dissipate stress by a small amount of frictional sliding and shear mechanisms thereby preventing brittle failure of these composites and increasing their fracture toughness. The mechanisms that redistribute and dissipate mechanical stress also render the composites insensitive to thermal shock. This has been successfully demonstrated at both room and elevated temperatures ${ }^{3,4}$, .

\section{Experimental Procedure}

Silicon nitride powders were blended with $\mathrm{Y}_{2} \mathrm{O}_{3}$ and $\mathrm{Al}_{2} \mathrm{O}_{3}$ sintering aids and polymeric materials to generate the feedrod core which was encapsulated with a $\mathrm{BN}$ shell to produce the feedrods (small (2") and large (5" in diameter)) shown in Fig. 1. The blending process is described adequately in previous literature ${ }^{1-5}$. The feedrod is extruded down to a much smaller diameter, stacked and then extruded through a second pass. This forms the standard FM honeycomb structure with the BN phase continuous throughout the microstructure. For use in propulsion environments however, where there is a possibility of the BN phase reacting with combustion products and becoming brittle and glassy, a different architecture was preferred. Following the first pass, a shell of $\mathrm{Si}_{3} \mathrm{~N}_{4}$ is applied to the first pass bundle and extruded to generate a tertiary microstructure where the $\mathrm{Si}_{3} \mathrm{~N}_{4}$ phase is continuous and the $\mathrm{BN}$ phase is fully encapsulated, thereby providing additional protection against gaseous phases (such as moisture). Tertiary fibers were produced with two different fiber architecture scales $(0.34 \mathrm{~mm}$ and $2 \mathrm{~mm}$ diameter respectively) resulting in a cell size of approximately $50 \mu \mathrm{m}$ and $500 \mu \mathrm{m}$ as shown in Fig. 2. These were generated from fibers of $0.34 \mathrm{~mm}$ and $2 \mathrm{~mm}$ diameter respectively. In these tertiary microstructures the $\mathrm{Si}_{3} \mathrm{~N}_{4}$ shell phase surrounding each of the $\mathrm{Si}_{3} \mathrm{~N}_{4}$ cores and $\mathrm{BN}$ shell bundles, is a continuous phase which acts to protect the $\mathrm{BN}$ from the ingress and reaction with combustion gases.

The final extruded fiber is spooled onto a drum in a single layer of parallel fibers. This single layer of fiber is cut along the long axis of the cylinder thereby generating a single ply, single fiber thick, uniaxially aligned layer which can be stacked to create oriented laminate designs (such as $0^{\circ} / 90^{\circ}$ or quasi-isothropic) as with conventional composite ply lay-ups. In the present study only uniaxially aligned structures were evaluated for thermal shock resistance. Following the layer stacking sequence to generate the required designs, the plates were thermocompressed to produce a solid plate and subjected to a binder burnout cycle in nitrogen and post oxidative treatment to remove all organic binders. These plates are then mounted in a 3" by 6" wide die and hot-pressed at between $1750^{\circ} \mathrm{C}$ and $1800^{\circ} \mathrm{C}$ for 1 hour, under nitrogen with a $4 \mathrm{kpsi}$ pressure applied perpendicular to the laminate direction. This resulted in a microstructure that shows a squashing of the cells in the pressure direction as can be seen in Fig. 2 
where the pressing direction was across the page. The dense plates were removed from the die, cut and machined to size for various thermal shock tests.
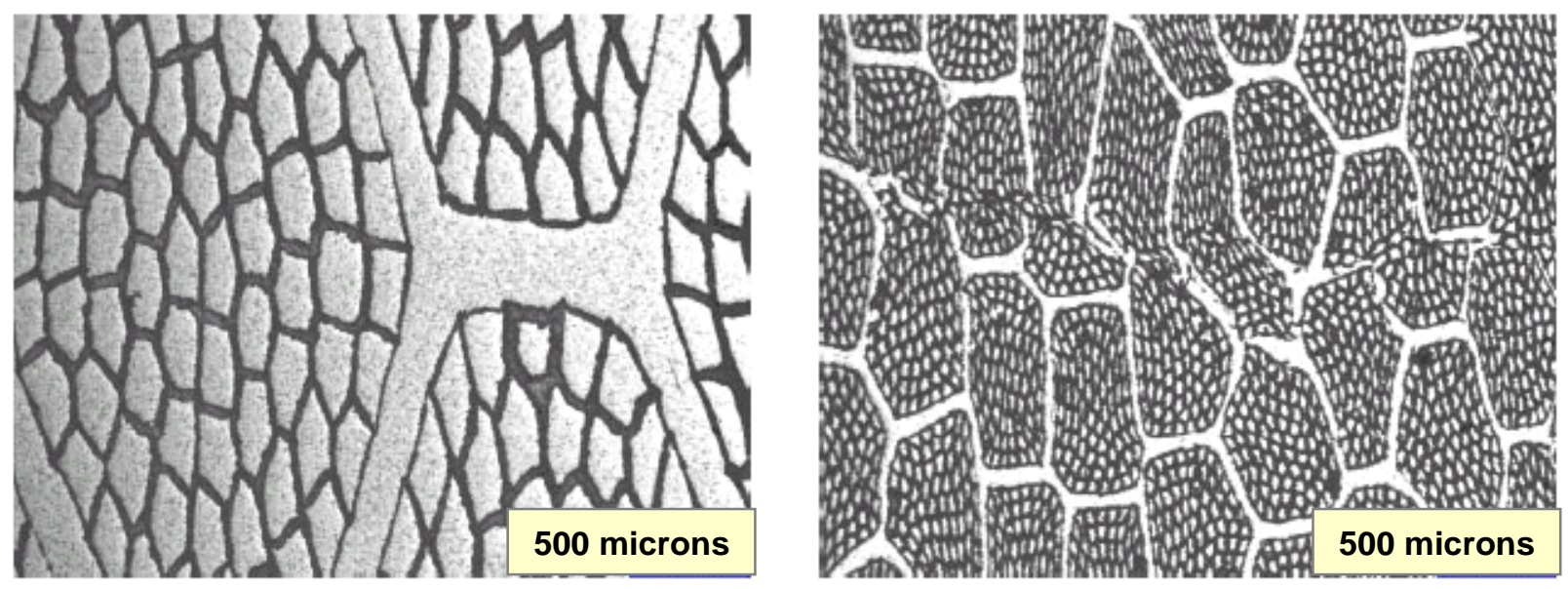

Figure 2. Optical micrographs of the large (left) and small (right) filament cell samples used in the thermal shock evaluations

Flexural strength Type B specimens were machined from the hot pressed FM material and from monolithic $\mathrm{Si}_{3} \mathrm{~N}_{4}$ containing the same sintering additives and processed under the same conditions. Attempts were made to produce a monolithic plate of $\mathrm{BN}$ for property evaluation but consolidation was not possible and no data was generated for the BN material. Flexural specimens were collected from 12 positions along the 6" length of the specimen, and spatial variations monitored to evaluate processing uniformity. Early presses showed significant process strength variations from end to end.

The samples for water quench tests were rectangular bars $\sim 3 \times 4 \times 50 \mathrm{~mm}$. Two batches of FMs with two different filament sizes were evaluated and tested in four-point bending before and after the thermal shock tests. Samples were heated to temperatures of $200,400,600,800$, and $1000^{\circ} \mathrm{C}$, equilibrated for 30 minutes and then dropped into a room temperature water bath to induce thermal shock. Mechanical and elastic properties of the samples were measured using bend tests and a nondestructive ultrasound technique respectively before and after thermal shock testing to determine the extent of damage. The behavior of samples exposed to thermal fatigue was also characterized by quenching the same samples repeatedly from $600^{\circ}$ or $1000^{\circ} \mathrm{C}$ into the water bath at $25^{\circ} \mathrm{C}$ and measuring changes in Young's modulus to assess the progression of damage induced by thermal fatigue. Examination by optical metallography before and after testing was performed to characterize the nature of the damage.

\section{Experimental Results}

\section{A. Strength Comparisons}

The average flexural strength of the monolithic $\mathrm{Si}_{3} \mathrm{~N}_{4}$ containing similar sintering additives $\left(\mathrm{Al}_{2} \mathrm{O}_{3}\right.$ and $\left.\mathrm{Y}_{2} \mathrm{O}_{3}\right)$ to those used in the FM lay-ups was approximately $840 \mathrm{MPa}$. The average flexural strength of the sinboron FM specimens was approximately $580 \mathrm{MPa}$ and $550 \mathrm{MPa}$ for the large and small cell configurations respectively, in a uniaxial lay-up as summarized in Table I together with data from different fiber orientations.

Table I. Physical and mechanical properties for monolithic and $\mathrm{FM} \mathrm{Si}_{3} \mathrm{~N}_{4} / \mathrm{BN}$ specimens

\begin{tabular}{|c|c|c|c|c|c|}
\hline Sample i.d. & $\begin{array}{c}\text { Composite } \\
\text { Lay-up }\end{array}$ & $\begin{array}{c}\text { Density } \\
\left(\mathrm{g} / \mathrm{cm}^{3}\right)\end{array}$ & $\begin{array}{c}(\%) \text { theoretical } \\
\text { density }\end{array}$ & $\begin{array}{c}\text { Youngs Modulus } \\
(\mathrm{GPa})\end{array}$ & $\begin{array}{c}\text { Flexual Strength } \\
(\mathrm{MPa})\end{array}$ \\
\hline Monolithic $\mathrm{Si}_{3} \mathrm{~N}_{4}$ & - & 3.25 & 99.19 & $345 \pm 33$ & $837.7 \pm 91.0$ \\
\hline $\mathrm{Si}_{3} \mathrm{~N}_{4} / \mathrm{BN} \mathrm{FM}$ & Uniaxial arrangement & 3.05 & 98.00 & $280 \pm$ na & $584.0 \pm 80.0$ \\
\hline $\mathrm{Si}_{3} \mathrm{~N}_{4} / \mathrm{BN}$ FM & Uniaxial arrangement & 3.05 & 98.00 & $250 \pm \mathrm{na}$ & $550.0 \pm \mathrm{na}$ \\
\hline $\mathrm{Si}_{3} \mathrm{~N}_{4} / \mathrm{BN}$ FM & 36 layers $0 \% 90^{\circ}$ & 3.00 & 95.82 & $308 \pm 8.6$ & $458.4 \pm 41.5$ \\
\hline $\mathrm{Si}_{3} \mathrm{~N}_{4} / \mathrm{BN}$ FM & 24 layers $0 \% 60^{\circ} / 60^{\circ}$ & 3.05 & 97.41 & $247 \pm 19.4$ & $451.6 \pm 51.4$ \\
\hline
\end{tabular}

The flexural strength of the hot pressed "sinboron" plates initially showed a lower strength overall and a significant drop in strength at either end of the 6" long specimens. Process improvements in the binder burnout 


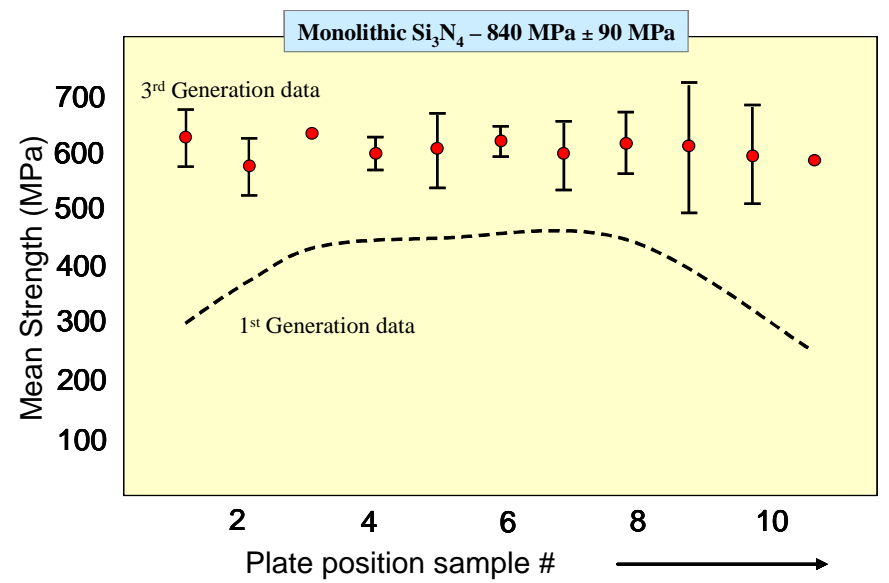

Figure 3. Improvement in FM strength uniformity across the 6" long hot pressed specimen stage and the hot-pressing stages allowed the strength to be improved and made more uniform across the specimen area as shown in Fig. 3.

In their green state the FM parts contain a large amount of organics ( $40 \%$ to $50 \%$ by volume) which must be removed prior to densification. In the early process schedules, insufficient time had been placed in these binder removal steps giving rise to small amounts of residual carbon which inhibited densification and led to lower overall strengths. During hot pressing, migration of these contaminants the outer edges of the silicon nitride plates as the part is elevated to a higher temperature than that observed during the binder removal stage led to a drop in strength around the edge of the FM specimen plates as shown in Fig. 3. The $2^{\text {nd }}$ and $3^{\text {rd }}$ generation materials were subjected to an extension

in the burnout schedule and also a change in the binder removal atmosphere leading to both an improvement in the strength and a more uniform strength distribution across the entire sample, clearly shown in Fig.3.

The formation of the FM composite structure which contains approximately $17.5 \mathrm{vol} \% \mathrm{BN}$ leads to a loss in strength of approximately $20 \%$ for a uniaxially aligned composite over the monolithic material. Other lay-up configurations such as the $0^{\circ} / 90^{\circ}$ led to a further decrease in strength from approximately $580 \mathrm{MPa}$ to $460 \mathrm{MPa}$ as half of the $\mathrm{Si}_{3} \mathrm{~N}_{4}$ fibers now lie orthogonal to the stress direction and do not contribute significantly to the strength. Similarly for the $0^{\circ} / 60^{\circ} /-60^{\circ}$ lay-up where only one third of the fibers were aligned in the major stress direction.

The FM architecture with a smaller cell size was expected to provide a higher overall strength than the large microstructure but actually showed a reduction in strength from approximately $580 \mathrm{MPa}$ to $550 \mathrm{MPa}$. One possible cause of this is the introduction of "flaws" during the fiber extrusion and subsequent densification process which at this small scale may provide regions of thicker BN sections, that could act as significant flaws at this scale.

\section{B. Thermal Shock Evaluation}

The as-fabricated strengths of the large and small celled FM uniaxially aligned specimens were measured at approximately $580 \mathrm{MPa}$ and $550 \mathrm{MPa}$ respectively. Following quenching into water from temperatures ranging from $200^{\circ} \mathrm{C}$ to $1000^{\circ} \mathrm{C}$ it was observed that there was no significant loss in strength up to a temperature of $600^{\circ} \mathrm{C}$ for either the small or large celled structures as shown in Fig. 4. From $800^{\circ} \mathrm{C}$ an approximate $10 \%$ strength loss was observed.
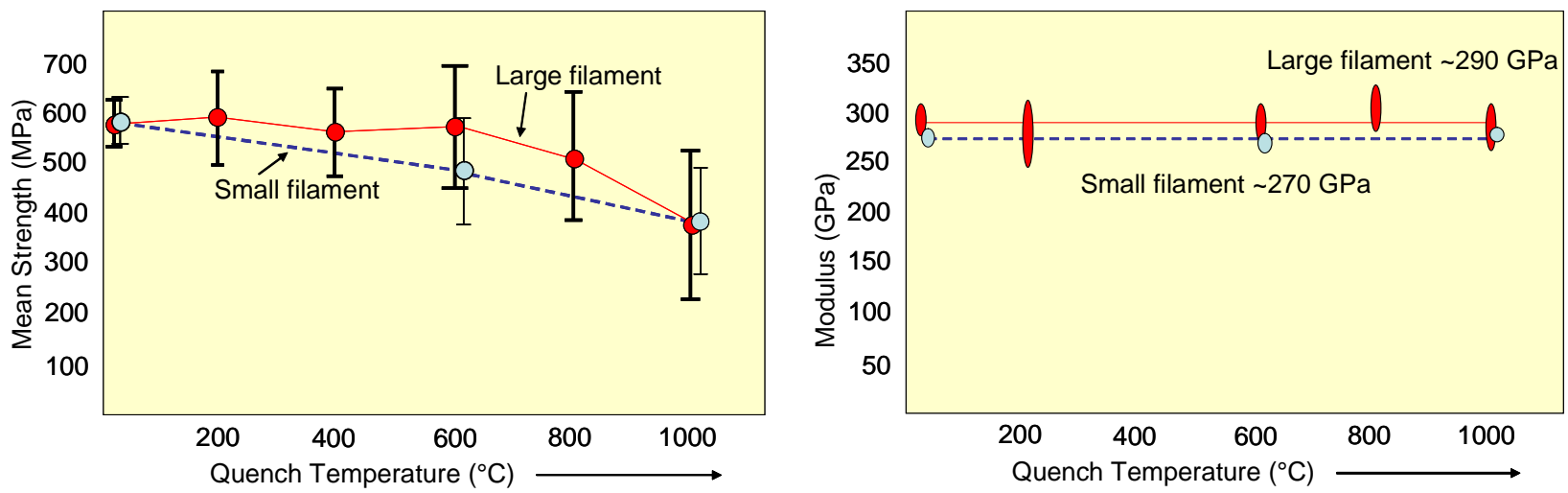

Figure 4. Change in flexural strength and modulus of uniaxially aligned sinboron subjected to thermal quench temperatures ranging up to $1000^{\circ} \mathrm{C}$. 


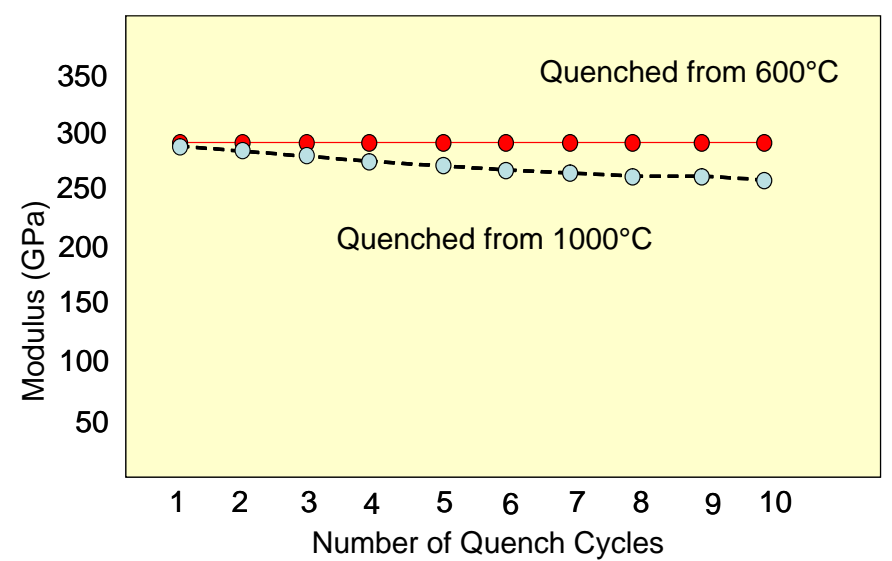

Figure 5. Change in modulus with repeated thermal quenches from $600^{\circ} \mathrm{C}$ and $1000^{\circ} \mathrm{C}$ - Large celled FM.

The modulus of the material was not seen to change appreciably over the entire range of quench temperature and remained constant at 290 $\mathrm{GPa}$ and $270 \mathrm{GPa}$ for the large and small celled structures respectively.

The effect of repeated thermal cycles on the large celled structure was evaluated and the results are summarized in Fig. 5. When quenched repeatedly from $600^{\circ} \mathrm{C}$ there was no measurable effect on the modulus which remained constant at $290 \mathrm{GPa}$, but when quenched from $1000^{\circ} \mathrm{C}$ a drop in the modulus was observed. The modulus dropped to approximately $260 \mathrm{GPa}$ (approximately 10\%) over 10 cumulative quenches from $1000^{\circ} \mathrm{C}$.

Microstructural evaluation by optical microscopy did not identify any obvious flaws within either the $\mathrm{Si}_{3} \mathrm{~N}_{4}$ or $\mathrm{BN}$ phases after thermal quench which might have led to this drop in modulus. Specimens were sectioned and observed in directions both parallel to and orthogonal to the fiber direction as illustrated by a typical micrograph shown in Fig. 6.
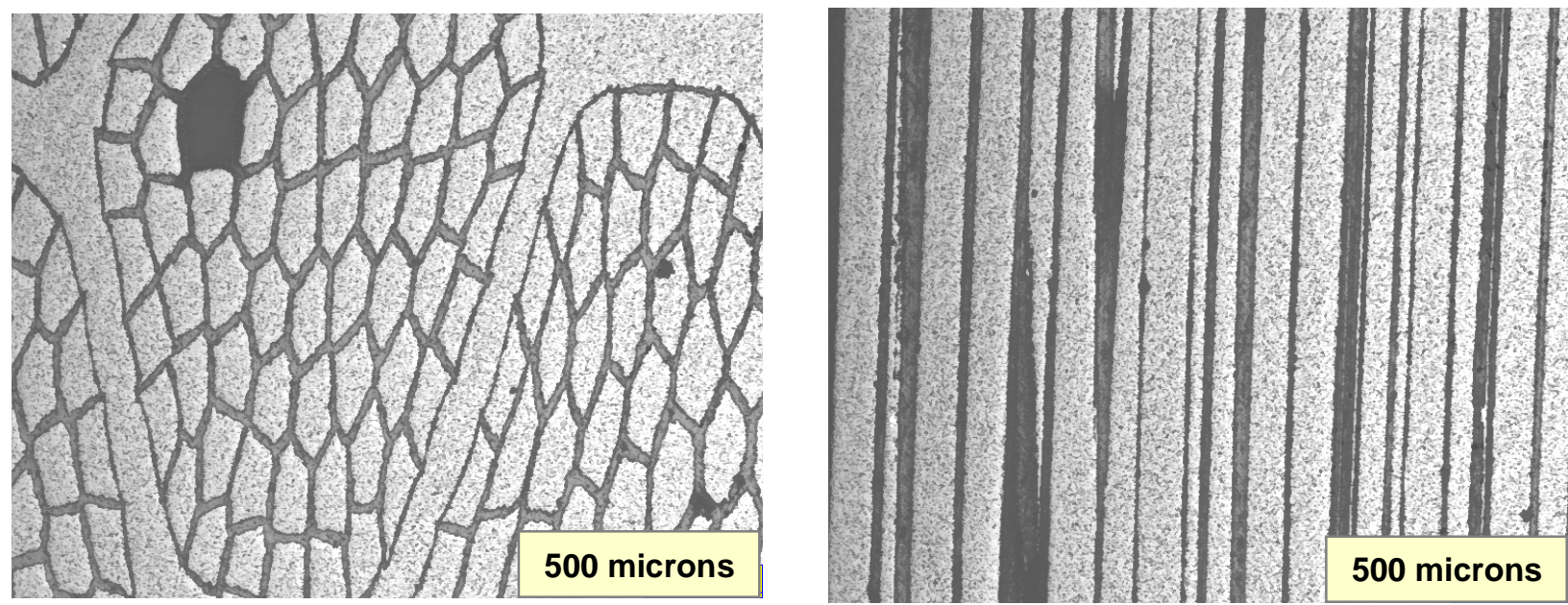

Figure 6. Optical micrographs of the large celled FM following quenching from $600^{\circ} \mathrm{C}$, perpendicular (left) and parallel (right) to the fiber direction.

\section{Response to Bending Load}

When loaded in flexure, the tertiary FM configuration showed very little load retention following initial failure. This is characteristically different from the "normal" $\mathrm{FM}$ configuration where each of the $\mathrm{Si}_{3} \mathrm{~N}_{4}$ fibers is surrounded by a BN phase and able to slip and fail in a graceful manner. The different response of these two FM configurations is shown in Fig. 7 and show fracture behavior substantially similar to monolithic $\mathrm{Si}_{3} \mathrm{~N}_{4}$ for the tertiary FM configuration. The "normal" graceful failure has been studied extensively by Halloran et.al. and can be seen from the micrograph insert to be able to generate substantial load retention ${ }^{6}$ even when badly damaged.

The tertiary FM configurations are able to support a greater load however, due to the continuous nature of the $\mathrm{Si}_{3} \mathrm{~N}_{4}$ shell around the individual "sinboron" fiber bundles, which must fail first in flexure before slipping of the BN phase can be accommodated. Very little elongation is observed from the tertiary configuration which shows a rapid drop off in strength after what appears to be the proportional limit is reached. 

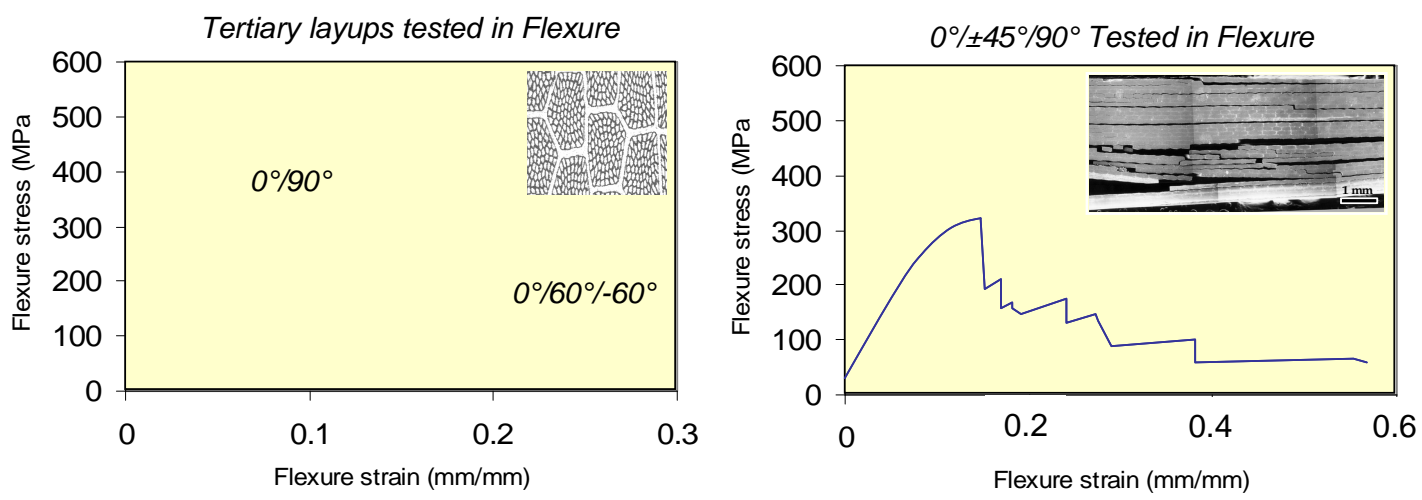

Figure 7. Stress strain response for the tertiary (left) and normal (right) FM configurations showing a significantly more brittle behavior for the tertiary fiber configurations tested in flexure.

\section{Discussions}

This work to evaluate the thermal shock response of a tertiary fiber configuration, sinboron FM material was completed in support of a much larger effort to develop a suitable material for non-load bearing components in "hot sections" of gas turbine engines in an effort to improve durability over their existing metallic counterparts. "Normal" FM configurations (with each of the $\mathrm{Si}_{3} \mathrm{~N}_{4}$ cells surrounded by a $\mathrm{BN}$ shell), have been evaluated thoroughly and have shown improved thermal shock response over monolithic $\mathrm{Si}_{3} \mathrm{~N}_{4}$ specimens of the same composition. Halloran and Young-Hag $\mathrm{Koh}^{6}$ have shown that for quench temperature above approximately $1100^{\circ} \mathrm{C}$ the FM configuration retains it's strength of approximately $300 \mathrm{MPa}$ whereas monolithic $\mathrm{Si}_{3} \mathrm{~N}_{4}$ retains very little strength. For materials to operate successfully within a combustion environment for many hundreds of hours however, some form of oxidation/hydration protection needs to be applied to the BN phase to stop oxidation and the formation of a brittle boric oxide glass. One approach was to investigate the addition of additives to the BN phase in order to understand and inhibit the ingress of oxygen ${ }^{6}$ and the other is to investigate the formation of a tertiary FM phase where each of the primary sinboron bundles is encapsulated in a second $\mathrm{Si}_{3} \mathrm{~N}_{4}$ shell, thereby leaving no $\mathrm{BN}$ exposed to the atmosphere except at the ends where the section might be orthogonal to the fiber direction.

The first generation tertiary material fabricated under this effort exhibited a average flexural strength of approximately $300 \mathrm{MPa}$ and showed a wide range of property variation across the billet. This was attributed to poor binder removal and the retention of residual carbon within the structure. Uniaxial specimens of this first generation material were evaluated by NAVAIR (G.Richardson) ${ }^{7}$ in a gas burner test rig where they were subjected to multiple thermal cycles to $950^{\circ} \mathrm{F}$ in realistic combustion environments and shear. Following 500 cycles to $925^{\circ} \mathrm{C}$ the samples showed an increase in average strength from approximately $216 \mathrm{MPa}$ to $235 \mathrm{MPa}$ in flexure. The thermal cycle was 15 seconds at RT followed by a 15 second rise time and 30 seconds at temperature. On inspection it was seen that some of the failures occurred around regions where the $\mathrm{BN}$ shell had become oxidized resulting in brittle failure across both the $\mathrm{Si}_{3} \mathrm{~N}_{4}$ and $\mathrm{BN}$ phases.

Later generations of specimens produced following changes to the binder removal and densification process showed that the average strength of the tertiary FM material was improved to $580 \mathrm{MPa}$. This was compared with an average strength of $838 \mathrm{MPa}$ for a monolith $\mathrm{Si}_{3} \mathrm{~N}_{4}$ with the same sintering additives, representing an approximate reduction in 30\% for the uniaxial tertiary FM configuration over that of the monolithic. While a direct comparison between the FM and monolithic ceramic materials was not measured in this study, previous work by Halloran ${ }^{6}$ had shown that the thermal shock resistance of the FM configuration is superior due to microcracking of the BN and the ability of the BN to accommodate strain thereby minimizing or delaying the formation of cracks of a critical scale. In the present water quench study very little difference was observed between the response of the tertiary FM configuration with a large $(150 \mu \mathrm{m})$ cell and small $(30 \mu \mathrm{m})$ cell size. The large cell size showed a higher strength (580 MPa vs. $550 \mathrm{MPa}$ ) and slightly higher modulus (290 GPa vs. $270 \mathrm{GPa}$ ) over the smaller cell size specimens respectively. It is thought that this might be due in part to a larger number of fiber imperfections or thinning of the BN shell in the smaller celled specimens, due to inconsistencies in the coextrusion process at the smaller scale. During quenching at temperatures up to $600^{\circ} \mathrm{C}$ no change in either the strength or modulus was measured for either cell size. For a quench temperature of $800^{\circ} \mathrm{C}$ a slight drop in strength (approximately $10 \%$ which might be statistically significant) was observed. At $1000^{\circ} \mathrm{C}$ a noticeable drop in strength was observed for both the small and large celled materials although there was no measurable drop in modulus. When exposed to multiple (10) thermal 
cycles from $600^{\circ} \mathrm{C}$ no change in elastic modulus was observed, but a small and continuous drop in the modulus was measured from $1000^{\circ} \mathrm{C}$. It is expected that this is a result of small accumulations of damage throughout the FM microstructure within the $\mathrm{BN}$ phase. No damage was observed within the $\mathrm{Si}_{3} \mathrm{~N}_{4}$ phase following the $1000^{\circ} \mathrm{C}$ quench, but with multiple quenches this may also be a potential failure mechanism.

The formation of a tertiary FM configuration while offering some additional protection to the BN phase against oxidation in combustion environments, reduces the overall toughness of the material and appears to significantly reduce graceful failure in response to bending loads, as would be expected. The tertiary configuration however, still offers good resistance to thermal shock to a temperature up to approximately $800^{\circ} \mathrm{C}$. The water quench method used to rapidly change the sample temperature is a very severe thermal shock technique due to the high thermal capacity of the water which unlike combustion gases can accommodate large amounts of heat and therefore give rise to a very rapid change in temperature within the specimen. In an engine configuration it is also expected that the quench would only occur from one surface. In the water quench method the complete skin of the specimen would be put into tension as the sample shrinks around a hotter interior once again providing a more severe thermal shock environment than that expected in engine use.

The ability to orient different fiber layers while further reducing the overall strength along a specific axis, add the ability to design to accommodate for a range of predicted stress configurations. Selected architectures have been fabricated and are presently awaiting engine testing as a non-load bearing fuel shield component that will reduce maintenance time and cost.

\section{Acknowledgements}

The authors would like to thank Dr Steve Fishman from the Office of Naval Research Arlington VA, who supported this work under contract N00014-03-C-0329, "Development and Fabrication of Low Cost Fibrous Monolith Composites for Propulsion Components". We would also like to thanks Irene Spitsberg at GEAE for valuable discussions on data interpretation.

\section{References}

${ }^{1}$ D. Popovic, W. Halloran, G.E. Hilmas, G.A. Brady, S. Somers, A. Barda, G. Zywicki, "Process for Preparing Textured Ceramic Composites" United States Patent No. 5,645,781, July 8 ${ }^{\text {th }}, 1997$.

${ }^{2}$ W.S. Coblenz "Fibrous Monolithic Ceramic and Method for Production" United States Patent No. 4,772,524, Sept $20^{\text {th }}, 1998$.

${ }^{3}$ G.E. Hilmas, A. Brady and J.W. Halloran, "SiC and $\mathrm{Si}_{3} \mathrm{~N}_{4}$ Fibrous Monoliths: Non-Brittle Fracture From Powder Processed Ceramics Produced by Coextrusion,"; pp. 609-614 in Ceramic Transactions-Vol. 51 Ceramic Processing Science and Technology. Edited by H. Hausner and G. Messing. American Ceramic Society Westerville, OH, 1993

${ }^{4}$ G.E. Hilmas, A. Brady, U. Abdali, G. Zywicki and J.W. Halloran, "Fibrous Monoliths: Non-Brittle Fracture from Powder Processed Ceramics," Mat. Sci. \& Eng. A., 195, 263-268 1995

${ }^{5}$ D. Kovar, B.H. King, R.W. Trice, and J.W. Halloran, "Fibrous Monolithic Ceramics" J. Am. Ceram. Soc., 80, [10] 2471-2487, 1997

${ }^{6}$ J.W.Halloran, S.C. Pillai and S.Karlsdottir "Oxidation of silicon nitride - boron nitride laminates", Amer.Ceram. Soc., Cocoa Beach Symposium $27^{\text {th }}$ January 2005.

${ }^{7}$ G.Y. Richardson, C.S. Lei, D. Alexander and R.N. Singh, "Environmental Effects on Ceramic Composites", Cocoa Beach Restricted Session, January 2004. 